DOI: $10.17805 / g g z .2017 .5 .2$

\title{
К вопросу о рациональной системе показателей состояния и развития научной сферы *
}

\author{
О. Э. БАШИНА, В. Н. НИКОЛЕНКО \\ МОСКОВСКИЙ ГУМАНИТАРНЫЙ УНИВЕРСИТЕТ
}

В статье рассматривается действующая система показателей состояния науки, критикуются отдельные ее положения. Рассматриваются показатели, которые должны более объективно и в большем соответствии с природой научного знания отражать состояние научной сферы.

Ключевые слова: фундаментальная наука; прикладная наука; разработки; эффективность науки; показатели науки

\section{On the Question of a Rational System of Indicators of the Status and Development of the Scientific Sphere

\author{
O. E. BASHINA, V. N. NIKOLENKO
} \\ MOSCOW UNIVERSITY FOR THE HUMANITIES}

The article examines the current system of science indicators, some of its separate provisions are criticized. The authors discuss indicators, which should reflect the conditions of the scientific sphere more objectively and in greater conformity with the nature of scientific knowledge.

Keywords: fundamental science; applied science; technological developments; effectiveness of science; science indicators

\section{ВВЕАЕНИЕ}

Аействующий в настоящее время набор показателей состояния науки (научной сферы) представляет собой совокупность, в основном, финансовых показателей (затрат и так называемой «результативности» исследований и разработок), а также показателей публикационной активности, цитируемости и патентной активности (в разрезе международных сопоставлений) (Индикаторы науки 2016, 2016), которые оказываются наиболее значимыми при оценке эффективности научных организаций и научных сотрудников. В статистических сборниках приводятся обобщенные дан-

* Исследование выполнено при финансовой поддержке РФФИ в рамках следующих проектов: «Разработка подходов к созданию системы оценки состояния и определения перспективных направлений развития научной сферы» (№ 16-02-00407), «Исследование потенциала отечественных производителей по обеспечению импортозамещения на потребительском рынке с использованием технологий Big Data» (№ 17-02-00718), «Возможности научно обоснованного выбора приоритетных направлений экологизации сельскохозяйственного производства и повышения его экономической эффективности» (№ 16-06-00029).

The research was pursued with financial support from the Russian Foundation for Basic Research within the frameworks of the following projects: "Elaboration of Approaches to the Development of the System for the Evaluation of the Condition and Determination of Promising Trends in the Development of the Scientific Sphere" (no. 16-02-00407), "Research on the Russian Producers' Potential for the Support of Import Substitution in the Consumer Market Based on Big Data Technologies" (no. 17-02-00718), "Opportunities of Scientifically Substantiated Choice of Priority Areas for the Ecologization of Agricultural Industry and Increase of Its Economic Efficiency" (no. 16-06-00029). 
ные о кадровом составе научных организаций и вузовской науке, характеристики материально-технического обеспечения (в денежном выражении).

\section{НЕКОТОРЫЕ ОСОБЕННОСТИ АЕЙСТВУЮЩЕЙ СИСТЕМЫ ПОКАЗАТЕАЕЙ}

Весь набор таких показателей ${ }^{1}$, как предполагается, должен отражать состояние научной сферы в Российской Федерации, а с учетом временно́й динамики - давать также возможность краткосрочного прогноза ее развития.

Такой набор показателей в качестве интегральных, сопоставительных данных оказывается, безусловно, полезным. Так, например, в работе «Фундаментальные исследования в современной России» приводятся графические данные (на 2013 г.) о российских расходах на науку в международном сопоставлении и о корреляции их с количеством публикаций (рис.). В то же время, табличные данные, приводимые в упомянутом обзоре ВШЭ, не позволяют наглядно представить соотношение между финансированием науки в различных странах. Смысл сказанного становится ясным из примера (таблица 1).

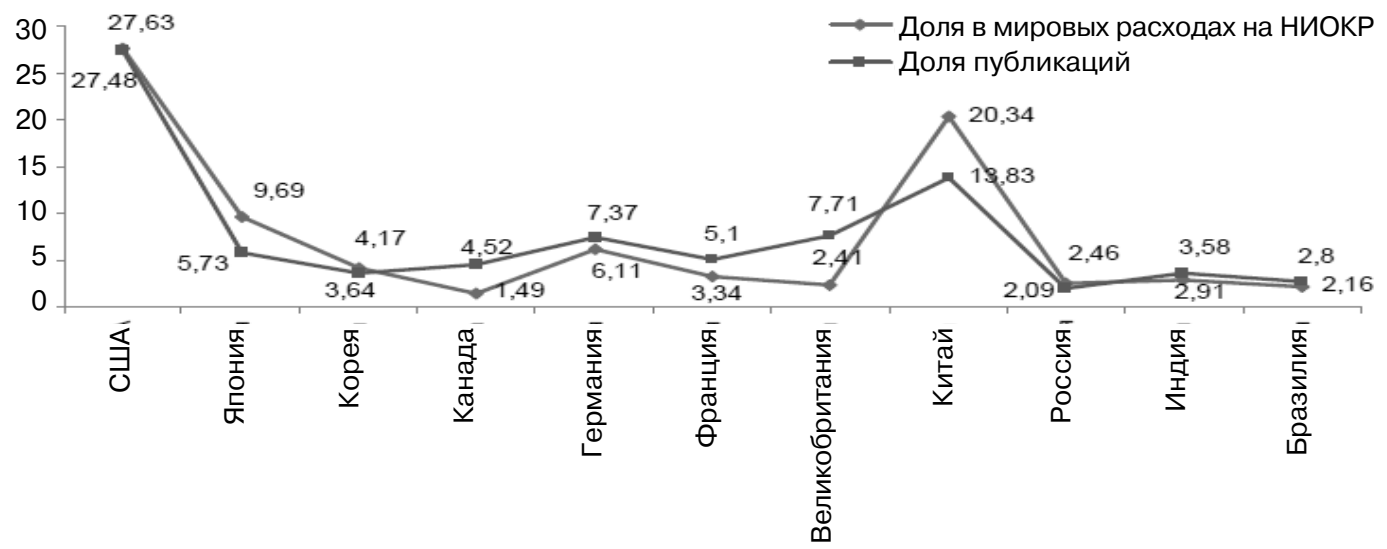

Расходы на науку и научные публикачии крупнейших экономик мира, 2013 г.

Expenses on science and research publications in the world's major economies, 2013.

Такое сопоставление может для некоторых показаться поводом для оптимизма: структура затрат на фундаментальные и прикладные исследования и разработки в России и США - наиболее передовой в научном плане в настоящее время стране практически совпадают! Однако если все же вспомнить (таблица 8.1, график 8.2 того же обзора) о содержательном сопоставлении, то видится совершенно иная картина (таблица 2).

Абсолютные расходы на науку в США более чем в 10 раз превышают такой показатель для России, затраты на одного исследователя в США почти в 3,5 раза больше, чем в России.

Таким образом, хоть и не сразу, но можно увидеть, пусть даже в финансовом выражении, всю меру не только отставания, но и меру незаинтересованности как российского государства, так и бизнеса в научных исследованиях и разработках, несмотря на то, что - и это очевидно для всех развитых стран - именно и только наука, а вовсе не конечные нефтедоллары, способна вывести Россию из затяжного системного кризиса. 
СТРУКТУРА ВНУТРЕННИХ ТЕКУЩИХ ЗАТРАТ

Таблища 1

НА ИССАЕАОВАНИЯ И РАЗРАБОТКИ (\%), 2014 Г.

Table 1

THE STRUCTURE OF INTERNAL OPERATING EXPENSES ON RESEARCH AND DEVELOPMENT (\%), 2014.

\begin{tabular}{|l|c|c|c|c|}
\hline & $\begin{array}{c}\text { Bнутренние } \\
\text { текушие затраты } \\
\text { на исследования } \\
\text { иразработки }\end{array}$ & $\begin{array}{c}\text { Фундаментальные } \\
\text { исследования }\end{array}$ & $\begin{array}{c}\text { Прикладные } \\
\text { исследования }\end{array}$ & Разработки \\
\cline { 2 - 5 } Россия & 100 & 16,4 & 19,5 & 64,1 \\
США & 100 & 16,5 & 19,2 & 64,3 \\
\hline
\end{tabular}

Таблииа 2

НАГАЯАНОЕ СОПОСТАВ АЕНИЕ РАСХОАОВ НА НАУКУ В РОССИИ И США, 2014 г. ${ }^{2}$

Table 2

COMPARISON OF EXPENSES ON SCIENCE IN RUSSIA AND THE USA, 2014.

\begin{tabular}{|l|c|c|c|}
\hline & $\begin{array}{c}\text { Bнутренние затраты } \\
\text { на исследования } \\
\text { и разработки, } \\
\text { млндолл. США }\end{array}$ & То же в\% к ВВП & $\begin{array}{c}\text { Tо же в расчете } \\
\text { Ра одного исследователя, } \\
\text { Росс. долл. США }\end{array}$ \\
\cline { 2 - 4 } США & 43440,6 & 1,19 & 99,9 \\
\hline
\end{tabular}

\section{Состояние науки и публикационная активность}

Как писал академик В. И. Вернадский в своей фундаментальной работе «Философские мысли натуралиста» ${ }^{3}$, «такое жизненное значение науки, входящее в сознание современного человечества, далеко не отвечает исторически, т. е. исходя из прошлого, сложившемуся реально ее положению и ее оценке в жизни. <...> Но требования науки не сформулированы, конкретно их неизбежность и польза для человечества не осознаны...» (Вернадский, 1988: 90-91; курсив источника. - О. Б., В. Н.). И далее там же: «В бюджетах отдельных государств такого рода вопросы в слабом (выделено нами. - О. Б., В. Н.) развитии могут подыматься и подымаются в государственных ассигнованиях... В общем, они ничтожны по сравнению с предстоящими задачами» (там же: 92).

По словам лауреата Нобелевской премии академика Ж. И. Алферова, реальное состояние российской науки - «это невостребованность ее результатов экономикой». Этот тезис повторен им многократно (Жорес Алферов о будущем ... , 2014: Электронный ресурс). Следовательно, действующая уже на протяжении достаточно Алительного периода система показателей состояния и развития научной сферы, призванная отражать как «результативность», так и соответствие науки потребностям общества, оказывается, во-первых, лишь условно информативной, и, во-вторых, не дает реальных ориентиров для улучшения дел в научной сфере.

Это можно объяснить несколькими причинами. 
Начнем с проблемы публикаций и цитирования. В настоящее время уже очевидно, что ориентация практически всей науки на публикацию результатов исследований в изданиях, индексируемых в Web of Science и Scopus - платформы, принадлежащие иностранными организациями - является принципиально ошибочной. По мнению А. И. Орлова, «бесспорно требование о первоначальной публикации в российских журналах результатов исследований, выполненных на деньги российских налогоплательщиков. Тот, кто делает первую публикацию за рубежом, наносит экономический ущерб нашей стране. Искусственное стимулирование роста числа публикаций, погоня за числом цитирований, большими значениями индекса Хирша и импакт-факторов журналов привела к созданию коммерческих структур, паразитирующих на науке. В нашей стране стало обычным взимание платы с авторов за опубликование статьи, в то время как еще 10-15 лет назад публикация была бесплатной, а 25-30 лет назад авторы получали гонорары за статьи» (Орлов, 2014: 1265).

Более того, даже и в этой ситуации возможность публикации научных результатов отдельным исследователем или малой группой оказывается часто нереализуемой: для этого попросту нет денег, или же публикация может появиться через много месяцев (и даже лет), когда ее актуальность будет утрачена.

Кроме того, публикация результатов прикладных исследований может быть нежелательна либо прямо запрещена вследствие требований соблюдения государственной или коммерческой тайны. Что в этом случае делать отдельным ученым и научным коллективам?

Еще одним проблемным вопросом оказывается цитирование. Индекс Хирша, несомненно, содержательный показатель, однако в нем не учитываются, например, такие паразитные для российской науки явления, как самоцитирования и перекрестные цитирования. Однако для современных электронных изданий выявить подобные факты не составляет сложной задачи. Необходимо выработать набор правил, которые позволяли бы отделять содержательные ссылки от чисто «количественных», и применять результирующие индексы к российским, прежде всего, публикациям и изданиям.

Единственной разумной альтернативой нынешним показателям публикационной активности является нормативно закрепленное требование о публикации результатов исследований российских ученых в отечественных научных изданиях (в том числе и в электронных, что позволит ускорить процесс публикации, а также снизить ее стоимость), а также вернуться к практике гонораров 4 , по крайней мере, для публикаций, пользующихся значительным интересом читателей. При этом государство должно обеспечить если и не бесплатный доступ к электронным изданиям, то уж, во всяком случае, плата должна быть чисто символической.

\section{«РЕЗУАБТАТИВНОСТЬ» ФУНААМЕНТААЬНОЙ И ПРИКАААНОЙ НАУКИ}

Следующей причиной неудовлетворительности нынешней системы показателей является то, что одинаковыми критериями оцениваются и фундаментальная, и прикладная наука. Если к прикладной науке экономические оценки в какой-то мере и применимы, то фундаментальная наука в принципе затратна, и к ней ни в коей мере не должны относиться требования экономической «результативности». Возможно, мерой ценности фундаментальных результатов могли бы служить индексы обращений к соответствующим публикациям, в особенности - обращений из зарубежных стран, а также мнение современного экспертного сообщества. 
Однако проблематика эффективности науки оказывается гораздо глубже, нежели финансовая «результативность».

Современная эпистемология рассматривает немалое количество вариантов методологии «добывания» нового научного знания и механизмов его развития5. Как правило, рассматривается проблематика, относящаяся к фундаментальной науке, однако многие положения применимы и к прикладной науке, и даже к области "разработок», т. е. к переходу от результатов прикладной науки к технологиям. По мнению авторов, к достоинству всех современных философских концепций науки относится их принципиальная совместимость. Это не означает, что все они в конкретной обстановке справедливы одновременно, но каждая из них отражает процессы получения нового знания в тех или иных условиях. Обобщенным результатом, схемой взаимодействия частей научного знания (фундаментальной $(\Phi)$ и прикладной $(П)$ науки и разработок $(\mathrm{P}))$ оказывается последовательность типа $\Phi \rightarrow \Pi \rightarrow$ Р. В действительности же, если рассматривать все разделы всех наук и соответствующие разработки, то подобная обобщенная схема превращается в сложнейший многосвязный граф, причем - в зависимости от этапности как исследований, так и разработок - вообще говоря, не трехуровневый. Кроме того, совокупность влияний в таком графе заведомо неоднонаправленна. Что это означает для целей управления наукой и выработки показателей ее эффективности?

Ясно, что движение типа $\Phi \rightarrow \Pi \rightarrow$ Р означает, что некоторые фундаментальные результаты могут быть использованы в прикладных исследованиях, которые, в свою очередь, создают почву для технологических разработок. Такое движение возможно при соответствующей квалификации и заинтересованности всех участников процесса (ученых или научных коллективов).

Авижение в обратную сторону, а именно $\mathrm{P} \rightarrow \Pi \rightarrow \Phi$, представляет собой отражение (общественного) заказа, причем этап $\mathrm{P} \rightarrow$ П реализуется, как правило, на уровне государственного заказа или же заказа корпораций. Этап $\Pi \rightarrow \Phi$ реализуется, по-видимому, в единичных случаях.

В государственном масштабе, следовательно, возникает вопрос: каким образом необходимо организовать движение $\mathrm{P} \rightarrow \Pi$, так, чтобы поставленные перед разработчиками и исследователями цели были достигнуты? При таком взгляде на ситуацию именно соответствие результатов исследований поставленным целям (задачам) и было бы естественной мерой эффективности науки.

Здесь хотелось бы подчеркнуть принципиальное отличие предлагаемого критерия (цель - задача - результат) от действующего показателя «результативности», который предписывает, чтобы в научном коллективе (в лучшем случае - рядом с ним) были «специалисты по внедрению», и чтобы сами ученые озадачивались вопросом «Где и как бы наше внедрить?». Совершенно ясно, что психология, образ мыслей, образ действий у ученого и менеджера-внедренца принципиально отличны, и бессмысленно требовать от ученых или научных коллективов «результативной» работы в таком ключе. Более того, можно, по-видимому, утверждать, что те субъекты, которые оказываются «результативными», являются уже, как правило, не действующими исследователями, но, - пусть и высокообразованными, высококвалифицированными, - управленцами, а это уже совсем иной вид деятельности, требующий иных талантов. 


\section{ЦЕАЕПОААГАНИЕ В НАУЧНОЙ СФЕРЕ}

Необходимо, очевидно, определиться, прежде всего, с целеполаганием, или даже с парадигматикой развития российской научной сферы в целом и ее отдельных (но не обособленных) разделов - наук. Из подобного явного и количественно осмысленного (в смысле значимости в рамках целеполагания) определения целей и парадигматики развития должны вытекать и количественно оцениваемые параметры развития научной сферы, и, естественно, возможность варьирования такими параметрами для определения перспектив и наиболее целесообразных условий развития научной сферы России.

Из даже поверхностного анализа взаимодействия этапов исследований и разработок следует, что ясное целеполагание оказывается основной проблемой повышения эффективности науки. К чему, каким научным результатам, какому новому знанию, превращаемому в технологии, должна стремиться наука? От этого должны зависеть и организация науки, и финансирование ее отраслей и отдельных исследований, и, в конечном итоге, не только конкурентоспособность государства, но его лидирующие, возможно, монопольные позиции на мировой арене, и не только в области технологий.

Проблема целеполагания развития научной сферы оказывается, при более-менее внимательном рассмотрении, далеко не тривиальной. Прежде всего, это связано с теми задачами, которые ставит перед собой государство в плане развития науки, научного потенциала, обеспечивающих науку отраслей и применения научных результатов. Такими задачами могли бы быть, например, следующие:

- достижение мирового уровня (и превосходство) в отдельных отраслях науки, в которых мировое сообщество видит магистральные пути ее развития;

- организация скорейшего развития тех отраслей науки, в которых страна получает неоспоримые конкурентные преимущества на мировой арене;

- ускоренное развитие отдельных областей фундаментальных исследований, обусловливающих их скорейшее применение в технологической сфере;

- развитие фундаментальных исследований, ориентированных, наоборот, на долгосрочную перспективу - естественно, с учетом сопутствующих рисков;

- развитие прикладных отраслей науки, ориентированных на полноценное удовлетворение потребностей социума (населения), и т. А.

Безусловно, все эти задачи оказываются взаимосвязанными, взаимозависимыми и частично пересекающимися. Тем не менее, весьма важной видится расстановка необходимых приоритетов как по отраслям (группам отраслей) науки, так и по потребным темпам их развития.

В настоящее же время мы имеем во всех прогнозах и руководящих документах перечень «направлений», которые лишь повторяют озвученные мировые тенденции. Ситуация может напомнить лозунг «Аогнать и перегнать Америку!» эпохи правления Н. С. Хрущева, который, как известно, по многим показателям так и не удалось воплотить в жизнь.

Основные направления усилий государства в развитии научной сферы (например, нанотехнологии) являются, очевидно, отражением современных устремлений и достижений мировой науки. Однако, не подвергая сомнению целесообразность таких действий, необходимо отметить, что этим, по-видимому, не исчерпывается перечень направлений, которые необходимо интенсивно развивать российской науке, и, с другой стороны, успехами, например, ядерной и космической программ советская наука 
была обязана приоритетной заинтересованности и всемерной как материальной, так и кадровой поддержке государства

Несомненно, уже заявленные направления жизненно важны, однако ими не должны исчерпываться приоритетные для России тематики исследований, если ставить государственную задачу обеспечения лидерства хотя бы в некоторых областях. Это приводит к необходимости ясного формулирования целей и приоритетов развития государства ${ }^{6}$ - при участии искдючительно российского научного сообщества в комплексе национальных научных программ, задач и направлений исследований с конкретно сформулированными целями, сроками и объемами финансирования. Такой подход должен быть комплексным, отработанным на всей совокупности потенциальных исследований и разработок. И именно такой подход - от заказа - позволит объективно судить об эффективности (а не только о финансовой «результативности») науки, научных коллективов и организаций.

\section{О НЕКОТОРЫХ АОПОАНИТЕАЬНЫХ УСАОВИЯХ И ПОКАЗАТЕАЯХ, ОТРАЖАЮЩИХ ВОЗМОЖНОСТИ РАЗВИТИЯ НАУЧНОЙ СФЕРЫ}

Следующей проблемой, которую необходимо сформулировать в контексте настоящей статьи, является вопрос об условиях, необходимых (но, по-видимому, не достаточных) для реализации подобной программы. Эти же условия будут основанием для формулирования очередной группы показателей состояния и развития науки.

Аля фундаментальной науки это, прежде всего, независимость субъекта науки (ученого или коллектива) от мнений исполнительной власти, стабильность финансирования и отчетность, возможно, аттестация- не слишком частая - лишь перед научным сообществом, с применением критериев заинтересованности читателей и оценок экспертов. В этом случае можно надеяться на плодотворную работу ученых.

Аля прикладной науки, как уже было сказано, необходима заинтересованность заказчика, которая должна подкрепляться явным (финансовым, в том числе) интересом исполнителя, субъекта науки, причем не только в виде «оплаты труда», но и в виде некоторого участия в последующих прибылях на основании авторства. Критерием эффективности в таком случае (и она окажется высокой) будет мера соответствия полученного результата поставленной задаче.

Несомненно, такие условия будут отвечать целям развития российской науки, если они будут реализовываться на контрактной основе (возможно, контракты на 3-5 лет, либо контракты с конкретным заказчиком). Тем не менее, здесь есть свои сложности.

Во-первых, это лозунг о вузовской науке. О какой науке может думать преподаватель с действующими нормативами по учебной нагрузке? Аурно снятая калька с опыта ведущих американских университетов привела к тому, что российскому преподавателю, получающему невысокую зарплату, нередко приходится работать в двух, а то и в трех вузах, чтобы как-то обеспечить свою семью. Требовать со среднего вузовского преподавателя каких-либо научных достижений будет можно, лишь обеспечив ему (ей) достойную зарплату и предоставив учебную нагрузку, сопоставимую с нагрузкой преподавателей в американских университетах.

Во-вторых, это опять лозунг о вузовской науке. При выполнении условий предыдущего рассуждения станет очевидной неправомерность исключительного и даже избыточного 7 финансирования крайне малого числа вузов.

B-третьих, вопрос о заработной плате и других формах социального обеспечения, в целом - о социальном статусе ученого. По поводу не окладов, а совокупного до- 
хода в одной организации от научной и/или научно-организационной деятельности. В настоящее время принят показатель «средней зарплаты», который составляется нередко по принципу «средней температуры по госпиталю». Величину среднего дохода от научной деятельности необходимо сопровождать - для каждой организации - не только величиной его среднеквадратичного отклонения, но и сведениями о максимальных и минимальных значениях. Заведомо несправедливо, что в иных научных организациях и вузах доход руководства от основной деятельности превышает средний доход научного сотрудника (преподавателя) в 30-50, а то и более раз.

Еще одной проблемой оказывается ситуация с патентной активностью, и, соответственно, с ее числовыми показателями. Аолжны быть созданы условия для совершенствования этой части процессов $\Phi \rightarrow \Pi \rightarrow \mathrm{P}$.

В мире возникает как международная кооперация базовых научных исследований, так и международное разделение направлений инновационной активности между разными странами. Возможно, именно здесь мы можем занять очень интересную нишу и найти то, что нам следует делать. Россия богата талантами. Придумать и создать один әкземпляр чего угодно мы можем всегда. Запатентовать его - практически не получается: то денег нет, то времени, то терпения. Вот если бы государство создало банк патентов на условиях, взаимовыгодных и государству и изобретателю, то мы бы, наверное, превратились в самую мощную страну-патентодержателя. Это, прежде всего, относится к разработке, производству и внедрению новых современных технологий, т. е. осуществлению полного инновационного цикла. Но для этого надо готовить людей, решать вопросы выплат гонорара за изобретение, обеспечивать безопасность государства и передачи изобретений и технологий. Обидный парадокс: в соответствии с действующим законом о патентовании, если подача заявки и ее регистрация осуществляется государственной организацией, то патентодержателем является организация, а не непосредственный исполнитель. Аля примера в США, в этом случае, разработчику выплачивается $15 \%$ гонорара, в странах ЕС - 8-10\%, в России - 0\%. Поэтому в США регистрируется столько заявок, сколько во всех других странах вместе взятых, а изобретателю выгодно именно изобретать, а не внедрять свою разработку.

Творческий потенциал российских ученых очень высок, в том числе в вузах, - дайте только нормальную зарплату и время, чтобы подумать. Российская наука способна (и должна) быть мировым лидером. Аля это следует лишь ставить амбициозные разумные цели, разумно планировать и финансировать, а также разумно оценивать.

\section{ПРИМЕЧАНИЯ}

1 Еще раз подчеркнем: либо в финансовом выражении, либо в обобщенных количественных единицах или средних значениях.

2 Выборочные данные из разделов 8.1, 8.2, 8.8 обзора ВШЭ (Индикаторы науки 2016, 2016).

${ }^{3}$ Глава IV «Положение науки в современном государственном строе».

${ }^{4}$ Авторы понимают, что подобное пожелание в нынешних «коммерческих» условиях, в общем-то, утопично.

5 Признавая ограниченность списка, упомянем хишь таких авторов, как В. И. Вернадский, Т. Кун, К. Поппер, Н. Н. Моисеев, В. С. Степин, И. Аакатос, И. Пригожин, П. Фейерабенд, В. В. Ильин, Ст. Тулмин, Аж. Холтон.

6 Подчеркнем: не только цели и приоритеты деятельности государства (правительства)в текущий момент и на некоторый прогнозный период, но ценности, цели и приоритеты существования и развития страны, включая дальнюю перспективу.

7 К примеру, ВШЭ дофинансировали до того, что вуз организует физическую лабораторию, совершенно не отвечающую ни его профилю, ни задачам. 


\section{СПИСОК АИТЕРАТУРЫ}

Вернадский, В. И. (1988) Философские мысли натуралиста : [сборник : К 125-летию со дня рождения] / предисл. А. А. Яншина и др. ; примеч. И. И. Мочалова, К. П. Флоренского ; АН СССР. М. : Наука. 519, [1] с.

Жорес Алферов о будущем и настоящем российской науки. Научная Россия (2014) / Ж. И. Алферов, Г. Я. Красников [Электронный ресурс] // Mikron JSC - YouTube. 8 сентября. URL: https://www.youtube.com/watch?v=RvUuWC5 outI (дата обращения: 25.01.2017).

Индикаторы науки 2016 (2016) : статистический сборник / Н. В. Городникова, А. М. Гохберг, К. А. Аитковский и др. ; Нац. исслед. ун-т «Высшая школа экономики». М. : НИУ ВШЭ. $304 \mathrm{c.}$

Орлов, А. И. (2014) Наука как объект управления // Научный журнах КубГАУ. № 101 (07). C. $1243-1273$.

Аата поступления: 25.01.2017.

Башина Ольга Эмильевна - доктор экономических наук, профессор, заведующая кафедрой статистики, маркетинга и бухгалтерского учета Московского гуманитарного университета. Адpec: 111395, Россия, г. Москва, ул. Юности, 5. Тел.: +7 (499) 374-70-20. Эл. адрес: bashina_o_e@ mail.ru

Николенко Владимир Николаевич - кандидат технических наук, доцент кафедры прикладной информатики Московского гуманитарного университета. Адрес: 111395, Россия, г. Москва, ул. Юности, 5. Тел.: +7 (499) 374-70-18. Эл. адрес: nvnram@rambler.ru

Bashina Olga Emilievna, Doctor of Economics, Professor; Head, Department of Statistics, Marketing and Accounting, Moscow University for the Humanities. Postal address: 5 Yunosti St., Moscow, Russian Federation, 111395. Tel.: +7 (499) 374-70-20.E-mail: bashina_o_e@mail.ru

Nikolenko Vladimir Nikolaevich, Candidate of Technical Sciences; $\bar{A}$ ssociate Professor, Department of Applied Informatics, Moscow University for the Humanities. Postal address: 5 Yunosti St., Moscow, Russian Federation, 111395. Tel.: +7 (499) 374-70-18. E-mail: nvnram@rambler.ru

\section{Аля изитиования:}

Бапшина О. Э., Никоненко В. Н. К вопросу о рациональной системе показателей состояния и развития научной сферы [Электронный ресурс]// Горизонты гуманитарного знания. 2017, №5. URL: http://journals. mosgu.ru/ggz/article/view/598 (дата обращения: Ад.мм.гггг.). DOI: 10.17805/ggz.2017.5.2 